\title{
A Influência do Financiamento Público Não Reembolsável na Estratégia de Inovação: Um Estudo de Caso em uma Empresa do Setor de Componentes para Calçados no Vale do Sinos - RS
}

\author{
The influence of non-refundable public financing in innovation strategy: a case study \\ in components sector for footwear in the Vale do Sinos - RS \\ Rogério Santos da Costa ${ }^{1}$ \\ Clair Wingert Puffal ${ }^{2}$ \\ Daniel Pedro Puffal ${ }^{3}$
}

Artigo recebido em para publicação em jun./2014 e aceito para publicação em nov./2014

\begin{abstract}
RESUMO
O estudo tem como objetivo analisar o financiamento público não reembolsável e a sua influência na decisão estratégica de inovar em uma empresa do setor de componentes para calçados. Foram levantados os principais mecanismos para incentivar a inovação no Brasil e ações para facilitar o acesso de recursos pelas empresas. Por meio de um estudo de caso, coletou-se os dados de uma empresa do setor de componentes para calçados, cuja análise indicou que o financiamento não reembolsável à inovação, mesmo em uma empresa de um setor maduro e pouco inovativo, levou a empresa a interagir com universidades, gerou novos produtos, patentes, atuação em novos mercados, aumento dos níveis de produção e lucro, além da instalação de sua área de P\&D em um parque tecnológico.
\end{abstract}

Palavras-chave: Recursos públicos. Estratégias de inovação. Subvenção econômica. Parques tecnológicos. Interação universidade-empresa.

\section{ABSTRACT}

This study aims to analyze the non-refundable public funding for innovation in Brazil, as an economic subsidy to innovation strategy and its influence for companies in the footwear industry to innovate. We analyzed the main mechanisms for funding innovation in Brazil in pre-defined sectors. We also sought to conceptualize innovation, some types of innovation, the motivations and characteristics of companies seeking public funds to innovate. Through a case study, using semi-structured interviews, we collected the data from a firm of the footwear industry in the Vale do Rio do Sinos at RS. It was proved that the non-refundable public incentive for innovation had strong influence on the decision to innovate in the company.

Keywords: Public resources. Innovation strategy. Economic subsidy. Technology parks. Universityindustry interaction.

1 Doutor em Ciência Política-UFRGS, Professor e Pesquisador do Programa de Pós-Graduação em Administração dos Cursos de Graduação de Relações Internacionais e Economia da Unisul, Coordenador do GIPART, Pesquisa na área de Difusão Tecnológica, Desenvolvimento e Integração Regional interdisciplinarmente. E-mail: paralelosc@uol.com.br.

${ }_{2}$ Mestranda de Administração de Empresas pela Universidade do Vale do Rio do Sinos - UNISINOS - RS, Pós Graduada em Gestão Empresarial - UNISUL - SC, Graduada em Administração de Empresas UNIVERSIDADE FEEVALE - RS, Pesquisadora do Núcleo de Inovação e Transferência de Tecnologia - NITT UNISINOS.

${ }^{3}$ Doutorado em Administração pela Universidade do Vale do Rio dos Sinos com estágio doutoral na Friedrich Schiller Universität - Jena, Alemanha, Mestrado em Administração pela Universidade do Vale do Rio dos Sinos (2005) e graduação em Administração de Empresas pela Universidade do Vale do Rio dos Sinos (2000). Atualmente é professor pesquisador no Programa de Pós Graduação em Gestão e Negócios da UNISINOS e atua como gerente de pesquisa, desenvolvimento e inovação na Unidade Acadêmica de Pesquisa e PósGraduação da UNISINOS. Tem experiência na área de Administração, com ênfase em Administração de Empresas, atuando principalmente nos seguintes temas: Interação universidade-empresa, Inovação, Inovação colaborativa e Cooperação interorganizacional. 


\section{INTRODUÇÃO}

A inovação é uma das principais formas de ampliar a competitividade das empresas e viabilizar o crescimento econômico de um país. Sendo o Brasil um país emergente, composto por setores em busca de tecnologia e conhecimento para se estruturar de maneira consistente, tem a necessidade de criar mecanismos para o desenvolvimento da inovação sustentável nas empresas.

No Brasil, as mudanças econômicas, políticas e tecnológicas têm pressionado as empresas a reorganizarem suas estratégias, tanto em relação ao mercado quanto a sua estrutura, especialmente nos temas ligados à inovação em produtos e processos. O Estado também tem se movimentado nesse sentido, com a preocupação em manter as empresas brasileiras competindo mundialmente, intensificando a implantação de mecanismos de apoio e financiamento à inovação nos últimos anos, especialmente para as empresas do setor da tecnologia de informação e outras relacionadas a este setor.

No período de 2006 a 2008, 9,2 mil empresas utilizaram algum incentivo público federal para inovar (PINTEC, 2008). Segundo Arbix (2013), a estrutura industrial brasileira está mudando, e um número cada vez maior de empresas está internalizando a inovação em suas estratégias de crescimento. Para induzir um aumento da produtividade e competitividade da economia brasileira, o governo anunciou em 2013 um plano de $\mathrm{R} \$ 32,9$ bilhões, que foi construído a partir de uma articulação dos Ministérios, Agências e demais instituições e baseia-se em quatro pilares: foco na inovação, prioridade nos setores definidos pelo Plano Brasil Maior ${ }^{4}$, integração dos instrumentos de crédito (subvenção, cooperativo não reembolsável e investimento em participação) e descentralização do crédito e da subvenção para micro, pequenas e médias empresas. As ações de um dos pilares já estão sendo executadas por meio do Plano Inova Empresa, anunciado no mês de agosto de 2013 pelo governo brasileiro, no qual alocou $R \$ 1,2$ bilhões para o programa INOVACRED ${ }^{5}$, que descentraliza o financiamento da inovação para micro, pequenas e médias empresas, com receita anual de até 90 milhões.

\footnotetext{
${ }_{5}^{4}$ O Plano Brasil Maior é a política industrial, tecnológica e de comércio exterior do governo Dilma Rousseff.

5 O Programa INOVACRED é uma linha de crédito com recursos da FINEP que visa fomentar, por meio de financiamento, projetos de inovação de empresas para aplicação no desenvolvimento de novos produtos, processos, serviços ou aprimoramento dos já existentes, ou ainda, inovação em marketing. Esse apoio é concedido de forma descentralizada, por meio de agentes financeiros, que atuarão em seus respectivos estados ou regiões, assumindo o risco das operações.
} 
Além do financiamento direto da inovação há também a oferta de incentivos fiscais, que se destacam por reduzir o custo e o risco dos projetos de pesquisa e desenvolvimento (P\&D), e se apresentam de duas formas: dedução do imposto de renda e crédito fiscal.

Em novembro de 2009, a Financiadora de Estudos e Projetos - FINEP realizou um evento visando avaliar a contribuição do Programa de Subvenção Econômica para a inovação nas empresas brasileiras e o desenvolvimento nacional, com intuito de divulgar os resultados para a sociedade brasileira. Conforme a FINEP (2010), diversas empresas que utilizaram a subvenção econômica, dizem ter viabilizado novos negócios por passar a caracterizar a empresa como inovadora, não necessariamente tendo traduzido em vendas oriundas do projeto subvencionado. Outras empresas investiram em projetos fora de seu foco de negócio e não sabem como transformar em receita o que desenvolveram.

As empresas têm utilizado os financiamentos e incentivos, entretanto não há evidências de que esses recursos realmente gerem inovação, pois conforme a avaliação (FINEP, 2010), mais da metade das empresas não obteve receita proveniente do projeto subvencionado e sim de algum outro produto/prestação de serviços de que a empresa já dispunha.

O governo brasileiro estruturou linhas de fomento federais e estaduais, destinados à inovação, por meio de incentivos diretos, as chamadas subvenções econômicas para inovação nas empresas que, conforme a FINEP (2013), são instrumentos de política de governo largamente utilizado em países desenvolvidos, operados de acordo com as normas da Organização Mundial do Comércio. Essa modalidade de apoio financeiro consiste na aplicação de recursos públicos não reembolsáveis (que não precisam ser devolvidos) diretamente em empresas, para compartilhar com elas os custos e riscos inerentes a tais atividades. Lançado no Brasil em agosto 2006, esta foi a primeira vez que um instrumento desse tipo foi disponibilizado no País, e tem como bancos de fomento o FINEP, BNDES e fundações estaduais de pesquisa.

Outro movimento importante presente nas políticas públicas do governo brasileiro desde os anos 1990 é a criação e o fortalecimento dos parques tecnológicos, fomentando a geração de empreendimentos de base tecnológica. Estes parques, normalmente instalados junto às universidades, tendem a 
estabelecer um ambiente que incentive a relação das empresas com as universidades.

O presente trabalho é parte de uma pesquisa que busca entender a interação das empresas participantes de parques tecnológicos no Rio Grande do Sul (RS) e sua relação com as universidades. Desta forma, após uma entrevista em profundidade com dez empresas do Valetec - Parque Tecnológico do Vale do Rio dos Sinos, em Campo Bom - RS, chamou a atenção que apenas uma empresa havia sido beneficiada com financiamentos não reembolsáveis. Ressalta-se também que esta empresa pertence ao setor calçadista, uma indústria madura, que nos últimos anos, tem passado por uma profunda crise devido a concorrência de empresas instaladas na Ásia (PUFFAL; PUFFAL, 2014).

Portanto, o presente artigo tem como objetivo responder a seguinte questão de pesquisa: Como o financiamento público influencia na geração da inovação tecnológica em uma empresa do setor de componentes para calçados da região do Vale dos Sinos - RS?

Para responder a pergunta, por meio de um estudo de caso, pretende-se analisar quais são os recursos públicos disponíveis para inovação para as empresas do RS, verificar quais as motivações que levam estas empresas a buscar recursos públicos; e por fim, identificar se o incentivo público não reembolsável influencia na decisão estratégica de inovar da empresa que pertente ao setor de componentes para calçados da região do Vale dos Sinos no estado do Rio Grande do Sul.

Além desta introdução, o artigo é composto por uma seção em que é apresentada a fundamentação teórica, posteriormente apresenta-se o método utilizado na pesquisa, a descrição e análise dos dados coletados e, finalmente, as considerações finais.

\section{INOVAÇÃO}

No contexto econômico, Schumpeter (1982) em 1912, definiu a inovação como uma destruição criadora, capaz de desenvolver novas e melhores combinações produtivas, com consequente abandono de práticas antigas e obsoletas, considerando assim uma inovação como um novo uso de possibilidades. $O$ trabalho de Joseph Schumpeter sobre o desenvolvimento econômico influenciou as teorias da Inovação, contribuindo para a construção do conceito de inovação do Manual de 
Oslo (OECD, 2004) que diz que a "inovação é a implementação de um produto (bem ou serviço) novo ou significativamente melhorado, ou um processo, ou um novo método organizacional nas práticas de negócios, na organização do local de trabalho ou nas relações externas".

Pode-se afirmar que existem quatro tipos de inovações: de produto, que envolve mudanças significativas nas potencialidades dos produtos e serviços; de processo, que representam mudanças nos métodos de produção de distribuição; organizacionais, que refere-se à implantação de novos métodos tais como práticas de negócio e de marketing, que envolvem a implementação de novos métodos de marketing, incluindo mudanças no design (OECD, 2004).

A Inovação, no contexto organizacional é considerada como processo central dentro das organizações, associada com renovação e reciclagem de oferta com disponibilização ao mercado e vista como uma atividade genérica, que está vinculada à sobrevivência e crescimento (TIDD; BESSANT; PAVITT, 2008).

Segundo Bessant e Tidd (2009 p.20), a inovação faz uma grande diferença para as organizações, de todos os tipos de tamanho, pois se não houver mudanças na forma de oferecer e criar bens e serviços ao mundo, empresas correrão o risco de serem superadas por outras que o façam. Os autores também consideram que a inovação assume quatro diferentes dimensões de mudança (os "4Ps" da inovação): A inovação de produto, onde a empresa muda o produto e/ou serviço que oferece; A inovação de processo que muda a forma de criar, ofertar ou apresentar o produto e/ou serviço ao consumidor; A inovação de posição, que consiste na mudança no contexto em que os produtos e ou serviços são introduzidos; e a inovação de paradigma, que promove mudanças nos modelos mentais básicos que norteiam o que a empresa faz.

Freeman e Suete (1997) citam algumas características das firmas inovativas bem sucedidas do século $X X$ que foram: um forte desenvolvimento profissional interno, execução de pesquisas básicas, uso de patentes para obter proteção, tamanho suficientemente grande, disposição para correr riscos altos, empreendedorismo suficientemente forte para coordenar a $\mathrm{P} \& \mathrm{D}$, a produção e o marketing, entre outros. Estas tentativas de generalização das características podem ser testadas, até certo ponto, por meio de análise e comparação de estudos de caso de um grande número de inovações, mas a dificuldade está em não saber quanto eles são representativos no processo inovativo. 
Freemann e Suete (1997) também postulam que:

Firmas pequenas podem ter vantagens comparativas nos estágios iniciais e menos custosos do trabalho inventivo das inovações mais radicais, enquanto que as grandes firmas têm vantagens nos estágios finais, na melhoria e no aumento de escala das descobertas iniciais. Além disso, há significativas diferenças entre os diversos ramos industriais quanto ao desempenho relativo de firmas pequenas e grandes. (FREEMANN; SUETE, 1997. p.400).

Dentro desta perspectiva, Bessant e Tidd (2009) comentam que a relação entre o tamanho da empresa e o grau de inovação não é claro, pois grandes e pequenas empresas possuem diferentes vantagens e desvantagens. Para os autores, as grandes empresas estão mais aptas a explorar economias de escala e de escopo de inovação, pesquisa, desenvolvimento, produção e vendas, no entanto, estas empresas sofrem pelo alto nível de burocracia e podem negligenciar oportunidades de risco mais alto ou de volume mais baixo. Por outro lado, pequenas são menos burocratizadas e são capazes de prosperar em nichos de mercados menores, além de existir uma motivação para inovar muito mais alta em tais organizações. Entretanto, elas não dispõem de recursos internos e necessitam confiar mais em fontes externas de inovação e parcerias para desenvolver e explorar inovações.

Corder e Salles-Filho (2006) salientam que o desafio da inovação é grande, tornando-se maior considerando a necessidade crescente de recursos e a importância da coordenação no processo alocativo para um uso adequado e eficiente do capital, principalmente em países menos desenvolvidos, já que nestes a escala de acumulação para o investimento produtivo é menor, limitando em tese, ações "perdulárias" para o investimento em ciência, tecnologia e Inovação. Considerando que a promoção da inovação, devido aos níveis de incerteza envolvidos, baseia-se em comportamentos mais "perduláveis" do que os investimentos produtivos tradicionais (construção de plantas industriais, estradas, portos ECT...), os países em desenvolvimento têm maiores dificuldades em promover e fomentar a inovação, pois tem menor capacidade de mobilização de capital.

\section{FINANCIAMENTO E INCENTIVOS PÚBLICOS Á INOVAÇÃO}

As atividades de pesquisa, desenvolvimento e inovação necessitam e produzem informação e apresentam elevado incerteza e risco em relação aos resultados, 
gerando na empresa uma baixa propensão ao investimento com recursos próprios. Assim, surge a necessidade de financiamento das atividades de P\&D serem financiadas pelos governos (ARROW, 1962). Para Freeman e Soete (1997) essas incertezas podem ser de diversas naturezas, destacando a importância daquela relativa ao mercado, pois os investimentos relativos a $P \& D$ requerem um longo período de maturação, o que reforça a dificuldade de que o financiamento seja realizado com recursos próprios da empresa, pois estes certamente serão destinados a atividades com menor incerteza de retorno.

Atualmente, há uma teoria econômica consolidada que afirma que o apoio do governo para promover a inovação nas empresas privadas é claramente justificado (ARROW, 1962; CLARYSSE; WRIGHT; MUSTAR, 2009). Nos últimos anos, os programas de financiamento do governo às áreas de pesquisa e desenvolvimento têm se tornado cada vez mais popular (WALLSTEN, 2000). O apoio dos governos para promover a inovação nas empresas, sob a forma de subsídios, incentivos fiscais e empréstimos, incentiva o aumento da inovação e das atividades a ela relacionadas (BEUGELSDIJK; CORNET, 2002; ROMIJN; ALBALADEJO, 2002; SOUITARIS, 2002). De forma geral, os governos incentivam o crescimento econômico por meio do desenvolvimento da inovação e, apoiando projetos de P\&D com potencial para gerar elevadas taxas de retorno social (FELDMAN; KELLEY, 2006).

A participação do governo é fundamental para fomentar a inovação tecnológica no país, já que este está associado ao crescimento e ao desenvolvimento de uma nação. O principal papel do governo no que concerne à inovação tecnológica, conforme Fonseca (2001) é o de prover os incentivos corretos ao desenvolvimento e à difusão de ideias por parte do setor privado (ações indiretas), além de promover um ambiente político, econômico e institucional que incentive as organizações a investir em ciência, tecnologia, pesquisa e desenvolvimento.

Segundo Salermo e Kubota (2008), o Brasil foi construindo nestes últimos 25 anos, um sistema mais robusto de inovação associadas à implantação de pósgraduações e pela criação de fundos especiais para o financiamento da pesquisa. Em 2005, foi disponibilizado pelo governo um conjunto inédito de instrumentos de apoio à inovação, bem como designadas algumas instituições para ajudar nesse movimento. A Financiadora de Estudos e Projetos - FINEP é uma das instituições públicas de direito privado vinculada ao Ministério da Ciência e Tecnologia (MCT), 
destinadas a promover e financiar a inovação por meio da pesquisa científica e tecnológica nas empresas e Instituições Científicas (ICTs), mobilizando recursos financeiros reembolsáveis e não reembolsáveis para promover a inovação no Brasil (FINEP, 2013).

Araújo (2012) explica que uma firma pode acessar a FINEP por três caminhos. O primeiro, através de parcerias em projetos de cooperação universidade-empresa, financiados pela instituição. O segundo por meio de crédito a um juro subsidiado pelos fundos setoriais e o terceiro por intermédio da subvenção econômica ou subsídios diretos, oferecidos através de chamadas públicas. Já Corder (2008), destaca os principais mecanismos de financiamento e incentivo à inovação, que visam ampliar o montante de recursos financeiros e sua alocação nas atividades de inovação, tais como: Apoio financeiro reembolsável, Venture Capital e Private Equity, Incentivos fiscais e Apoio financeiro não reembolsável.

Estudos de Rapini, Oliveira e Silva Neto (2013), indicam evidências de que a natureza do financiamento público parece influenciar na motivação na cooperação entre empresas e universidades, pois induzem as empresas a participarem de projetos cooperativos de maiores risco, custo e complexidade.

\section{SUBVENÇÃO ECONÔMICA, APOIO FINANCEIRO NÃO REEMBOLSÁVEL}

De acordo com a FINEP (2010) a subvenção econômica à inovação é um dos principais instrumentos da política de fomento do governo, sendo operado de acordo com as normas da Organização Mundial do Comércio - OMC. Ela foi criada a partir da aprovação e da regulamentação da Lei de Inovação (Lei 10.973, de 02/12/2004) que é destinada à cobertura de despesas de custeio das atividades de inovação (pessoal, matérias primas, serviços de terceiros patentes, conservação e adaptação de bens imóveis destinados à inovação) e da Lei do Bem (Lei 11.196 de 21/11/2005) que destina-se ao ressarcimento de parte do valor da remuneração de pesquisadores mestres ou doutores contratados pelas empresas. Essa modalidade permite a aplicação de recursos não reembolsáveis diretamente em empresas brasileiras, que desenvolvam projetos de inovação estratégicos para o país, compartilhando os custos e os riscos inerentes a tais atividades.

Conforme Costa, Szapiro e Cassiolato (2013), o programa de subvenção econômica à Inovação começou a ser operado em 2006, por meio de editais competitivos através das chamadas públicas de Subvenção Econômica à Inovação, 
cuja base legal está na Lei da Inovação, sendo que os recursos são provenientes do Fundo Nacional de Desenvolvimento Científico e Tecnológico (FNDCT). O financiamento através de subvenção econômica se configura como um dos pilares da política de inovação e é considerado um subsídio aceitável, conforme o artigo $8^{\circ}$ do acordo da Organização Mundial do Comércio (OMC), tendo como principal característica, ser um instrumento não-reembolsavel, ou seja, não requer devolução do recurso ao órgão concedente. Por outro lado, existe um compartilhamento de riscos do projeto entre Estado e empresa, sendo que esta necessita apresentar uma contrapartida. Outro aspecto importante é o fato de não haver necessidade de apresentação de garantias para recebimento do recurso.

O objetivo do Programa destaca, segundo Costa, Szapiro e Cassiolato (2013), a referência ao desenvolvimento de "processos e produtos inovadores", fazendo com que os editais estabeleçam como premissa o apoio somente a projetos de inovação e não a projetos em etapas de pesquisa e desenvolvimento, evidenciando-se assim foco no projeto e seu resultado potencial e não na estratégia de inovação mais geral da empresa. Isto porque, o que se espera em caso de sucesso técnico, é que a empresa tenha condições necessárias para que 0 resultado do projeto subvencionado chegue ao mercado.

Os autores fizeram um levantamento de cinco editais, do ano de 2006 a 2010, apresentado no Quadro 1, em que verificaram que cada edital estabeleceu regras diferenciadas em relação: às áreas e temas que poderiam ser apoiados; à contrapartida exigida; porte da empresa; estabelecimento de valores de financiamento mínimo e máximo para as propostas, entre outros permitidos no Programa de Subvenção à Inovação.

Além dos critérios de submissão apresentados no Quadro 1, Costa, Szapiro e Cassiolato (2013), levantaram algumas mudanças nos critérios de submissão de projetos, decorrente de um aprendizado por parte da Finep ao longo dos anos. O edital de 2010 foi o que apresentou maiores alterações, sendo que foram incluídos novos critérios e informações não existentes ou não solicitadas em editais anteriores, seja na análise de projetos submetidos ou no acompanhamento dos projetos contratados. Entre as alterações estão o período de no mínimo dois anos de existência das empresas responsáveis pelo projeto; inclusão do limite de participação das empresas em apenas um projeto; apresentação de um plano de negócios relativo ao projeto. Assim, os critérios em todos os editais contemplam: 
capacidade técnica da equipe; grau de inovação dos projetos em relação a outros projetos ou soluções e o impacto esperado da inovação no país.

Quadro 1 - Critérios para submissão de Projetos de Subvenção, por Edital

\begin{tabular}{|c|c|c|c|c|c|}
\hline Critérios & Edital 2006 & Edital 2007 & Edital 2008 & Edital 2009 & Edital 2010 \\
\hline $\begin{array}{l}\text { Áreas } \\
\text { Apoiadas }\end{array}$ & $\begin{array}{l}\text { 1.Ações } \\
\text { horizontais } \\
\text { 2.Semi } \\
\text { condutores e } \\
\text { Software } \\
\text { 3.Fármacos e } \\
\text { medicamentos } \\
\text { 4.Bens e Capital } \\
\text { 5.Aeroespacial } \\
\text { 6.Nanotecnologi } \\
\text { a } \\
\text { 7.Biotecnologias } \\
\text { 8.Energias } \\
\text { alternativas }\end{array}$ & $\begin{array}{l}\text { 1.TI, } \\
\text { Comunicação e } \\
\text { Nanotecnologia } \\
\text { 2.Biodiversidade, } \\
\text { Biotecnologia e } \\
\text { Saúde } \\
\text { 3.Programas } \\
\text { Estratégicos } \\
\text { 4.Biocombustíveis } \\
\text { e Energia } \\
\text { 5.Desenvolviment } \\
\text { o Social }\end{array}$ & $\begin{array}{l}\text { 1.TI e } \\
\text { Comunicação } \\
\text { 2.Biotecnologia } \\
\text { 3.Saúde } \\
\text { 4.Programas } \\
\text { Estratégicos } \\
\text { 5.Energia } \\
\text { 6.Desenvolviment } \\
\text { o Social }\end{array}$ & $\begin{array}{l}\text { 1.TI e } \\
\text { Comunicação } \\
\text { 2.Biotecnologia } \\
\text { 3.Saúde } \\
\text { 4.Programas } \\
\text { Estratégicos } \\
\text { 5.Energia } \\
\text { 6.Desenvolviment } \\
\text { o Social }\end{array}$ & $\begin{array}{l}\text { 1.TI e } \\
\text { Comunicação } \\
\text { 2.Biotecnologia } \\
\text { 3.Saúde } \\
\text { 4.Programas } \\
\text { Estratégicos } \\
\text { 5.Energia } \\
\text { 6.Desenvolviment } \\
\text { o Social }\end{array}$ \\
\hline $\begin{array}{l}\text { Valor do } \\
\text { Edital }\end{array}$ & $\mathrm{R} \$ 300$ milhões & $\mathrm{R} \$ 450$ milhões & $\mathrm{R} \$ 450$ milhões & $\mathrm{R} \$ 450$ milhões & $\mathrm{R} \$ 500$ milhões \\
\hline $\begin{array}{l}\text { Contraparti } \\
\text {-da exigida }\end{array}$ & $\begin{array}{l}5 \% \\
\text { micro/pequeno } \\
\text { porte } \\
20 \% \text { pequena } \\
\text { empresa } \\
40 \% \text { médias } \\
\text { empresas } \\
60 \% \text { grandes } \\
\text { empresas }\end{array}$ & Não há* & $\begin{array}{l}5 \% \\
\text { micro/pequeno } \\
\text { porte } \\
20 \% \text { pequenas } \\
\text { empresas } \\
100 \% \text { médias } \\
\text { empresas } \\
200 \% \text { grandes } \\
\text { empresas }\end{array}$ & $\begin{array}{l}5 \% \\
\text { micro/pequeno } \\
\text { porte } \\
20 \% \text { pequenas } \\
\text { empresas } \\
100 \% \text { médias } \\
\text { empresas } \\
200 \% \text { grandes } \\
\text { empresas }\end{array}$ & $\begin{array}{l}10 \% \\
\text { micro/pequeno } \\
\text { porte } \\
20 \% \text { pequenas } \\
\text { empresas } \\
50 \% \text { médias } \\
\text { empresas } \\
100 \% \text { média- } \\
\text { grande } \\
200 \% \text { grandes } \\
\text { empresas }\end{array}$ \\
\hline $\begin{array}{l}\text { Valor } \\
\text { mínimo }\end{array}$ & $\mathrm{R} \$ 300 \mathrm{mil}$ & $\mathrm{R} \$ 500 \mathrm{mil}$ & $\mathrm{R} \$ 1$ milhão & $\begin{array}{l}\mathrm{R} \$ 500 \text { mil } \\
\text { micro/pequenas } \\
\mathrm{R} \$ 1 \text { milhão } \\
\text { médias/grandes }\end{array}$ & $\mathrm{R} \$ 500 \mathrm{mil}$ \\
\hline $\begin{array}{l}\text { Valor } \\
\text { máximo }\end{array}$ & Não há & Não há & Não há & 10 milhões & 10 milhões \\
\hline
\end{tabular}

${ }^{*}$ O Edital de 2007 não estipulou o percentual das contrapartidas, embora elas continuassem a ser necessárias, como exigência da Lei de Inovação e constituíssem um dos fatores considerados na análise e ordenamento dos projetos

Fonte: Costa, Szapiro e Cassiolato (2013).

Conforme o Quadro 1, a partir de 2008 houve uma estabilidade nas áreas apoiadas na evolução dos critérios para submissão dos projetos de subvenção por editais e na contrapartida exigida da empresa. Por outro lado, houve mudanças no valor mínimo e máximo de recurso por projeto a ser submetido.

A partir dos levantamentos teóricos e de dados secundários pertinentes ao assunto, tem-se a condição necessária de evoluir no estudo proposto, com a intenção de identificar qual a influência dos recursos públicos não reembolsáveis, na decisão de inovar numa empresa do setor de componentes para calçados. 


\section{METODOLOGIA}

Este trabalho procura aprofundar o aspecto que envolve a inovação com a utilização dos recursos públicos não reembolsáveis ofertados por órgãos de fomento no Brasil, com o objetivo de verificar a influência de recursos públicos, em forma de subvenção econômica, para o desenvolvimento da inovação no setor de componentes para calçados na região do Vale do Sinos, no RS, de forma a identificar quais foram suas motivações, dificuldades e compensações para gerar a inovação numa empresa deste setor.

Optou-se por uma abordagem de pesquisa qualitativa, que mantêm características únicas que são inerentes ao projeto como utilização de cenários naturais, onde ocorrem o comportamento humano e os fatos; dados descritivos; foco nas percepções e nas experiências dos participantes e na maneira que eles entendem sua vida; interesse particular em entender como as coisas ocorrem e atenção aos detalhes e não a suas generalizações entre outras (GRESWEL, 2007).

Neste artigo foi utilizado como estratégia de pesquisa o método de estudo de caso único, por tratar de um assunto pouco discutido no setor de componentes para calçados. Conforme Yin (2005), estudo de caso é uma investigação empírica que investiga um fenômeno contemporâneo, especialmente quando não existe definição clara entre o fenômeno e o contexto.

Para a coleta de dados, além de dados secundários disponibilizados pela FINEP e do BNDES, foram efetuadas três entrevistas em profundidade com representantes de uma empresa de componentes para calçados, situada na região do vale dos sinos, no RS. Optou-se pela entrevista semiestruturada porque esta compartilha com qualquer conversa, e oferece uma rica fonte de dados que proporciona acesso ao modo como as pessoas relatam tanto seus problemas como sua boa sorte (SILVERMAN, 2009). As entrevistas foram realizadas no mês de março de 2014, gravadas em um arquivo de áudio, posteriormente transcritas e analisadas, utilizando-se a análise de conteúdo de acordo com Bardin (1979). Foram entrevistados um dos diretores da empresa, o responsável pela área de pesquisa, desenvolvimento e inovação e também o responsável pela área de produção da empresa. 


\section{ANÁLISE E DISCUSSÃO DOS DADOS}

A empresa estudada está situada na cidade de Ivoti, na região do Vale do Rio dos Sinos (Figura 1) no Rio Grande do Sul - Brasil, e conforme a Associação do Comércio e da Indústria $(\mathrm{ACl})$, esta região é considerada um dos maiores cluster calçadista do mundo.

Figura 1 - Conselho Regional de Desenvolvimento do Vale do Rio dos Sinos

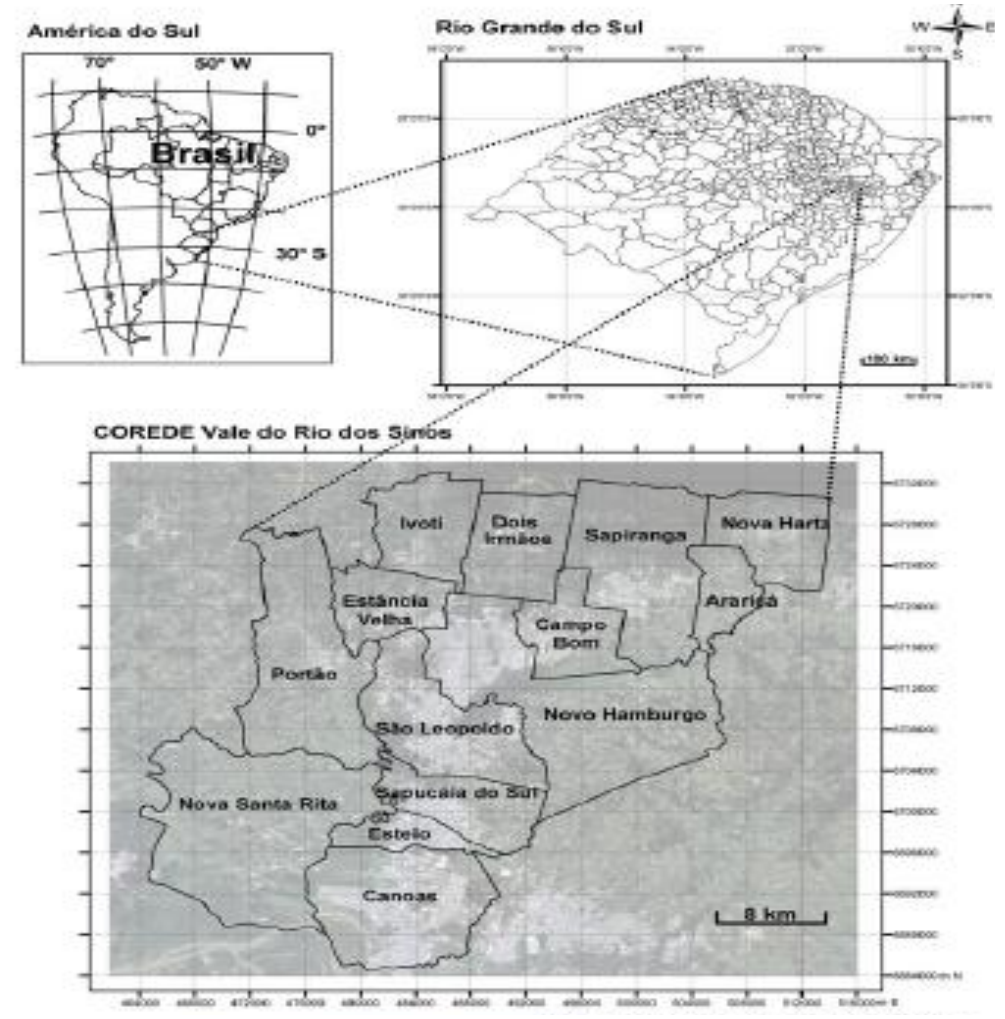

Fonte: ACINH, 2014.

A empresa iniciou suas atividades no RS, produzindo materiais em tecido e não tecido para cabedais e forros, principais componentes para a confecção de calçados, prestando também serviços de dublagens (colagem de dois materiais), atendendo às exigências do mercado calçadista e afins.

A partir de dados da Associação Brasileira de Empresas de Componentes para Couro, Calçados e Artefatos- Assintecal, foi verificada a evolução da utilização dos materiais para cabedal (Gráfico 1) entre 2004 e 2010. Apesar do couro ainda ser um dos principais materiais utilizados para a fabricação dos cabedais, houve diminuição de consumo de $54 \%$ para $37 \%$ no período analisado, sendo substituído pelo laminado de PVC, laminado de PU e Tecido. Essa substituição do couro pelos materiais sintéticos e tecidos, que fazem parte dos produtos oferecidos pela 
empresa estudada, reforça a necessidade de desenvolvimento tecnológico pela empresa para melhorar sua competitividade e além disso, colaborar para o desenvolvimento do setor de componentes para calçados da região do Vale dos Sinos, no RS que, apesar de ser um setor maduro, tradicionalmente inova pouco.

\section{Gráfico 1 - Evolução dos materiais no Cabedal}

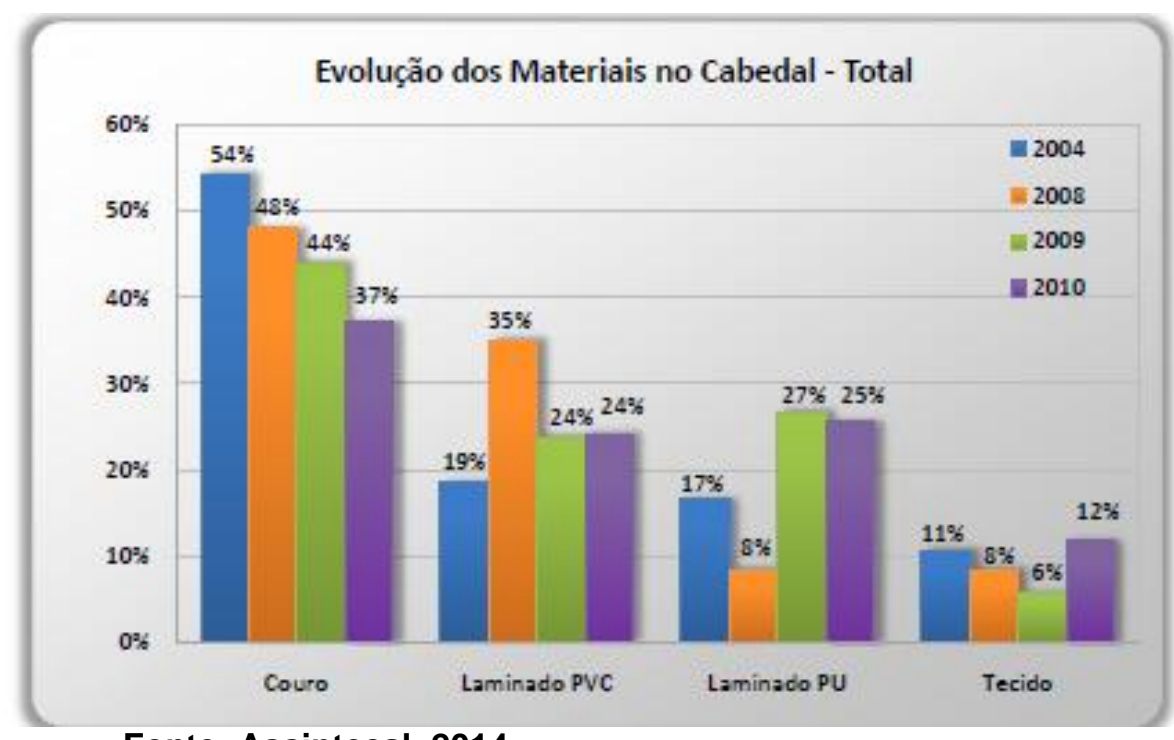

Fonte: Assintecal, 2014

Em 2003, no início das atividades da empresa estudada, com a entrada de produtos chineses e a oferta de bons produtos produzidos por grandes empresas brasileiras, foi percebida a perda de rentabilidade e redução da competitividade no setor de componentes para calçados. Os diretores estavam divididos em parar as atividades, ou seguir em frente e fazer algo diferente. Surgiu então a necessidade de reformular o planejamento estratégico, implementando ações como a pesquisa e desenvolvimento de tecnologias que agregassem valor ao produto oferecido. Conforme as palavras do responsável pela produção da empresa "... se ficássemos fazendo o comum, estaríamos perdendo mercado". Tal situação reflete ao que Bessant e Tidd (2009) afirmam de que a inovação faz uma grande diferença para as organizações, de todos os tipos de tamanho, pois se não houver mudanças na forma de oferecer e criar bens e serviços ao mundo, empresas correrão o risco de serem superadas por outras que o façam. Além disso, Tidd, Bessant e Pavitt (2008) consideram a inovação como um processo central dentro das organizações e vista como uma atividade genérica que está vinculada à sobrevivência e crescimento da empresa. 
Conforme o diretor da empresa, a aproximação com as entidades de classe da região, para obter maiores oportunidades de prospecção no mercado brasileiro e estrangeiro, por intermédio de palestras, participação em missões empresariais para mercados mais desenvolvidos como Estados Unidos, China e Europa, em feiras como a WSA, Modamont, Shoe and Leather, Techtextil, ITMA, projeto conforto (Colômbia e Equador), Inspiramais, Congressos e Seminários como Congresso de Biomecânica, Nanotec, Congresso de Inovação e Tecnologia da Assintecal e outros, foram estratégias muito importantes para seus resultados de inovação.

Possivelmente ações como a participação em atividades com associações de classe, a proximidade com equipes de pesquisa e desenvolvimento de empresas clientes, parceria com institutos de pesquisa e universidades, encaminharam as atenções da empresa, para as oportunidades em editais e tecnologias emergentes. Esta aproximação provavelmente influenciou para o desenvolvimento da inovação da empresa, pois a direção percebeu que existiam alternativas tecnológicas para melhorar seus produtos. Com o conhecimento adquirido, iniciou o processo de desenvolvimento de um produto funcional, através da nanotecnologia incorporada, isto é, um produto com funções além das básicas esperadas, como por exemplo, uma palmilha para calçados que, além de proporcionar conforto, elimina odores. Foi o início do desenvolvimento de uma inovação, onde a empresa muda o produto e/ou serviço que oferece, assumindo assim uma das quatro dimensões de mudança (os "4Ps" da inovação) de Bessant e Tidd (2009).

O responsável pelo $P \& D$ da empresa, ao salientar que inovar é um desafio que se torna ainda maior considerando a necessidade crescente de recursos para a pesquisa e desenvolvimento, confirma o que Corder e Salles-Filho (2006) destacam na literatura. Possivelmente o desafio colocado pelo P\&D, esteja relacionado ao tamanho da empresa, onde recursos são escassos para o desenvolvimento de novos produtos.

Para acessar a Finep, foi necessário recorrer a um dos três caminhos que Araújo (2012) sinalizou, referindo-se ao programa de subvenção econômica à inovação, oferecidos por meio de chamadas públicas em 2006, que prevê a concessão de recursos não reembolsáveis. O Objetivo do Programa, segundo Costa, Szapiro e Cassiolato (2013), é destacar a referência ao desenvolvimento de "processos e produtos inovadores". Dentro dessa linha, a empresa submeteu um projeto para o edital de Seleção Pública Chamada Pública MCT/FINEP/SUBVENÇÃO 
ECONÔMICA À INOVAÇÃO - 01/2006, na área de nanotecnologia, para incorporar nanopartículas de prata em têxteis para desenvolvimento de um tecido com propriedade antimicrobiana. Apesar dos diretores acharem que não haveria chances do projeto ser aprovado, por se tratar de uma empresa de pequeno porte, o projeto foi um dos selecionados, com o apoio financeiro de $\mathrm{R} \$ 500.000,00$ pela FINEP e contra partida da empresa de $\mathrm{R} \$ 140.000,00$. Com esse apoio, a empresa conseguiu dar continuidade no desenvolvimento inovador, através do projeto intitulado "NANOTECIDO - Incorporação de propriedades da nanotecnologia em materiais têxteis (palmilhas e forros) para calçados".

$\mathrm{Na}$ primeira fase do projeto, a empresa contou com a parceria de uma universidade para o desenvolvimento do processo da incorporação das nano partículas em tecidos. O resultado disto foi o lançamento de dez produtos inovadores para o mercado, sendo que cinco deles tiveram seus registros de patente encaminhados junto ao INPI. Considerando o que foi dito pelo responsável pela pesquisa e desenvolvimento da empresa, as ações de execução de pesquisa básica, uso de patentes para proteção e empreendedorismo para coordenar a pesquisa e desenvolvimento podem ser consideradas importantes para que a empresa se torne inovativa, já que ela apresenta três das seis características de firmas inovativas de sucesso do século XX, citadas por Freeman e Suete (1997).

Com a experiência do primeiro projeto, com a proximidade com equipes de pesquisa e desenvolvimento de empresas e o conhecimento adquirido pelo meio acadêmico, em 2010 a empresa submeteu um novo projeto, através do edital de seleção Pública MCT/FINEP/FNDCT - Subvenção Econômica à Inovação - 01/2010, na área da saúde, em parceria com outra universidade e mais uma empresa da área médica, para o desenvolvimento de um biofilme com nanocápsulas com óleos essenciais com propriedades terapêuticas, para desenvolver insumos para curativo para queimados. O nome do projeto submetido é "Desenvolvimento e industrialização de tecido nanofuncionalizado com ativo de liberação prolongada de atividade antimicrobiana, antiinflamatória, analgésica e cicatrizante, produzido à base de carragena para aplicação como insumo para curativos de ferimentos, queimaduras e procedimentos pós operatórios". O incentivo público recebido foi de $R \$ 1.600 .000,00$ e contra partida da empresa de $R \$ 400.000,00$, sendo que atualmente o produto desenvolvido já se encontra em fase de testes. Provavelmente na elaboração das fases do projeto, a direção já havia percebido a importância e os 
ganhos que a empresa poderia absorver através da aproximação entre a empresa e a universidade.

Com o conhecimento e a experiência adquiridos, inclusive por intermédio da execução dos projetos apoiados pela subvenção econômica, os diretores perceberam a necessidade de alterar a forma de gerir e desenvolver parte do envolvimento na pesquisa e desenvolvimento de novos produtos. Para isso, a empresa instalou parte de sua área de $P \& D$ no parque tecnológico Valetec, em Campo Bom - RS, que possui intima ligação com uma universidade da região. Assim, montou um laboratório com a função de simular os processos de fabricação, formar uma equipe capacitada em desenvolver novos produtos, obter agilidade nos ensaios, comprovações e laudos que transmitam confiabilidade e credibilidade para o mercado. Essa decisão de aproximar geograficamente o P\&D para um local próximo à universidade pode ter influência na busca de recursos subsidiados, pois a interação universidade empresa tem uma relação positiva no desenvolvimento de um produto inovador.

Apesar de a empresa achar que as dificuldades maiores para iniciar o processo de inovação seriam alocar os recursos através da subvenção e desenvolver o projeto, a colocação do produto no mercado e a regulamentação de uma das inovações pelos órgãos da saúde brasileiros foram as principais barreiras encontradas para que a inovação acontecesse com maior rapidez. Esta afirmação tem efeito pela experiência advinda do apoio recebido pela subvenção econômica de 2006. O produto foi lançado para o mercado em 2008, mas somente em 2012 a utilização dessa inovação foi percebida pelo seu cliente como um diferencial e uma forma de agregar valor ao seu produto final, que é o calçado. Segundo o responsável pela produção da empresa estudada “... a inovação só se concretiza quando o produto é aceito pelo mercado, caso contrário ela é apenas uma invenção", confirmando o que Freemann e Suete (1997) postulam de que firmas pequenas podem ter vantagens comparativas nos estágios iniciais, enquanto que as grandes firmas têm vantagens nos estágios finais. No caso da empresa estudada, por se tratar de uma pequena empresa, o processo inicial do projeto até sua concepção ocorreu num fluxo normal, mas logo enfrentou dificuldades em introduzir o produto para seus clientes, necessitando de recursos próprios para divulgar a inovação para o mercado. 
O diretor entrevistado salientou que houve algumas alterações nos editais de 2006 para o de 2010, com a inclusão de critérios tais como apresentação de defesa do plano de negócios do projeto, graus de inovação e impacto da inovação no país, que para ele, foram pertinentes para assegurar a qualidade dos projetos. Isto confirma o que Costa, Szapiro e Cassiolato (2013) comentam que, inicialmente o programa de subvenção era destinado às universidades e na ocasião do lançamento da subvenção para as empresas em 2006, foi utilizado o mesmo modelo, sendo necessário alguns ajustes nos editais seguintes. (COSTA, SZAPIRO e CASSIOLATO, 2013). A utilização da subvenção econômica possibilitou para a empresa estudada a oportunidade de adquirir conhecimento tecnológico, expertise e capacidade de manter uma vantagem competitiva no mercado de componentes para calçados, nas palavras do diretor: "(....) ० apoio recebido foi fundamental para o desenvolvimento da inovação na empresa, sem ele, a inovação não aconteceria ou talvez acontecesse, mas com bem menos investimento e muito mais tempo de desenvolvimento".

Quadro 2 - Resumo dos principais resultados do estudo

\begin{tabular}{|c|c|c|}
\hline & \multicolumn{2}{|r|}{ EDITAL SUBVENÇÃO FINEP } \\
\hline & ANO 2006 & ANO 2010 \\
\hline Valor do recurso recebido & $\mathrm{R} \$ 500.000,00$ & $\mathrm{R} \$ 1.600 .000,00$ \\
\hline Contrapartida da empresa & $\mathrm{R} \$ 140.000,00$ & $\mathrm{R} \$ 400.000,00$ \\
\hline \multirow[t]{2}{*}{ Nome do projeto submetido } & $\begin{array}{l}\text { NANOTECIDO - } \\
\text { Incorporação de } \\
\text { propriedades da } \\
\text { nanotecnologia em } \\
\text { materiais têxteis } \\
\text { (palmilhas e forros) } \\
\text { para calçados }\end{array}$ & $\begin{array}{l}\text { Desenvolvimento e } \\
\text { industrialização de tecido nano } \\
\text { funcionalizado com ativo de } \\
\text { liberação prolongada de } \\
\text { atividade antimicrobiana, anti- } \\
\text { inflamatória, analgésica e } \\
\text { cicatrizante, produzido à base } \\
\text { de carragena para aplicação } \\
\text { como insumo para curativos de } \\
\text { ferimentos, queimaduras e } \\
\text { procedimentos pós- } \\
\text { operatórios. }\end{array}$ \\
\hline & \multicolumn{2}{|c|}{ RESULTADOS } \\
\hline № produtos inovadores & 10 & Fase de testes \\
\hline $\begin{array}{l}\text { № de produtos inovadores } \\
\text { patenteados }\end{array}$ & 5 & A ser encaminhado \\
\hline Parcerias com Universidade & Sim & Sim \\
\hline
\end{tabular}




\begin{tabular}{|c|c|c|}
\hline Parceria com Empresas & Sim & Sim \\
\hline Parcerias com Institutos Tecnológicos & Sim & Sim \\
\hline Parcerias com Entidades de classe & Sim & Sim \\
\hline $\begin{array}{l}\text { Dificuldades burocráticas para a } \\
\text { efetivação a submissão ao edital até a } \\
\text { liberação do recurso }\end{array}$ & Não & Não \\
\hline $\begin{array}{l}\text { Dificuldades mercadológicas e } \\
\text { barreiras regulatórias }\end{array}$ & $\begin{array}{l}\text { Os produtos } \\
\text { lançados em } 2008 \\
\text { tiveram aceitação } \\
\text { pelo mercado } \\
\text { apenas em } 2012 .\end{array}$ & $\begin{array}{l}\text { O produto ainda está em fase } \\
\text { de regulamentação junto aos } \\
\text { órgãos regulatórios da saúde }\end{array}$ \\
\hline $\begin{array}{c}\text { Fatores que influenciaram a inovação } \\
\text { na empresa com recursos públicos } \\
\text { não reembolsáveis. }\end{array}$ & $\begin{array}{l}\text { Oferta de apoio fina } \\
\text { novos produtos; } \\
\text { Capacitação e conh } \\
\text { e desenvolvimento } \\
\text { Estruturação de um } \\
\text { Desenvolvimento nc } \\
\text { - Campo Bom-RS; } \\
\text { Melhorar a Competi } \\
\text { Conquistar crescime } \\
\text { Adquirir a confiabilic }\end{array}$ & $\begin{array}{l}\text { ceiro para desenvolvimento de } \\
\text { ecimento tecnológico, expertise } \\
\text { e competências para inovar } \\
\text { laboratório de Pesquisa e } \\
\text { Parque Tecnológico da Valetec } \\
\text { ividade; } \\
\text { nto econômico; } \\
\text { ade e credibilidade do mercado. }\end{array}$ \\
\hline
\end{tabular}

Fonte: Elaborado pelos autores a partir da coleta de dados.

O Quadro 2 apresenta os dados levantados, de forma resumida para um melhor entendimento, os fatores que influenciaram a empresa a buscar recursos públicos não reembolsáveis para inovar.

O diretor explica que o faturamento anual triplicou por ações de marketing desde 2004, sendo que 35\% do incremento foram decorrentes das inovações desenvolvidas através dos projetos aprovados em subvenções econômicas desde 2006. Estes dados encontram-se disponíveis no setor contábil e nas ferramentas de gestão da empresa.

Assim, conforme os relatos dos principais atores da empresa estudada, a subvenção econômica para inovação no Brasil, através de recursos não reembolsáveis, influenciou na decisão de desenvolver a inovação para obter conhecimento tecnológico e resultados econômicos, contribuindo para o desenvolvimento do setor do componente para calçados da região do Vale dos Sinos, no Rio Grande do Sul.

\section{CONSIDERAÇÕES FINAIS}


A partir do exposto nesse trabalho, pode-se observar que nos últimos anos o Brasil tem efetuado ações para mobilizar as empresas a serem mais inovadoras e assegurar a competitividade no mercado brasileiro e no exterior. O programa de incentivo à inovação, por meio da subvenção econômica com recursos não reembolsáveis lançado em 2006 foi um importante incentivador na busca desta competitividade.

Muitas empresas já utilizaram a subvenção econômica para inovação, conforme a FINEP (2010), mas poucas dizem ter desenvolvido uma inovação ou viabilizado algum tipo de negócio ou não sabem como transformar em receita a inovação que desenvolveram. Esta falta de evidências remete a mudanças nos critérios e estruturação do programa, necessárias para que as empresas adotem uma postura mais robusta quanto à inovação a qual querem gerar, através da submissão de projetos com um risco tecnológico mais elevado.

O setor de componentes para calçados da região do Vale dos Sinos, no RS, por ser um setor maduro, tradicionalmente inova pouco, apesar disso, a empresa estudada merece destaque no seu desempenho relativo a pesquisa, desenvolvimento e inovação. Sua trajetória de sucesso indica que o financiamento público não reembolsável para inovação teve uma influência significativa alavancando seus negócios, bem como contribuindo no desenvolvimento do setor de componentes para calçados. $O$ apoio através dos recursos influenciou na geração do conhecimento tecnológico, na competitividade mercadológica e no crescimento do faturamento advindos das inovações e competências adquiridas.

O fomento à inovação, por parte do financiador, levou a empresa estudada a interagir com as universidades, aumentando suas chances de acesso ao financiamento e especialmente acesso a novos conhecimentos. Outra decorrência desse processo foi a instalação da unidade de P\&D da empresa em um parque tecnológico, que levou a empresa a um novo patamar de pesquisa e desenvolvimento de novos produtos e processos, além de transmitir ao mercado sua imagem de empresa inovadora. Como resultado principal do acesso aos financiamentos na modalidade de subvenção, pode-se ainda destacar o desenvolvimento de novos produtos na empresa, pedidos de registro de patentes e a penetração da empresa em um novo mercado, gerando maiores níveis de produção e melhores resultados econômicos e financeiros. 
Apesar dos recursos públicos disponíveis, pode haver empresas que não inovam por acharem que são pequenas demais, ou que não tem capacidade de submeter um projeto que tenha uma inovação significativa. Cabe aos gestores buscar apoio junto às entidades e universidades para que suas empresas consigam utilizar o que está sendo oferecido pelos órgãos públicos.

Como o estudo em questão abordou a utilização de recursos financeiros, sob forma de subvenção econômica, utilizados por uma empresa de um setor maduro como o de componentes para calçados e que obteve êxito na busca de recursos não reembolsáveis, não é possível a sua generalização para o setor, devido a limitação do método escolhido. Entretanto, essa limitação favorece futuros estudos investigativos e com análises mais abrangentes para o acompanhamento das influencias das ações governamentais quanto ao estímulo à inovação por meio de subsídios financeiros em setores menos inovativos ou maduros.

\section{REFERÊNCIAS}

ACINH - Associação do Comércio e Indústria de Novo Hamburgo - Informações Socioeconômicas do Vale dos Sinos > http://www.acinh.com.br/download/72 Acessado em: 05 de setembro de 2014.

ARAÚJO, Bruno César - Políticas de Apoio à Inovação no Brasil: Uma Análise de sua evolução recente- IPEA/Textos para Discussão, Rio de Janeiro, 2012.

ARBIX, Glauco. Os Desafios da Descentralização. Revista Inovação em Pauta, Rio de janeiro, n.16, p.84-86, 2013.

ARROW, K. J. Economic welfare and the allocation of resources for invention. In: Nelson, Richard (Ed.), The Rate and Direction of Inventive Activity: Economic and Social Factors, Princeton University Press, Princeton, NJ, p. 609-629, 1962.

ASSINTECAL - Associação Brasileira de Empresas de Componentes para Couro, Calçados e Artefatos - Relatório IAPC - Índice Assintecal de Produção Calçadista/Julho de 2014.

BARDIN, L. Análise de conteúdo. Lisboa: Edições 70, 1979.

BESSANT, John; TIDD, Joe. Inovação e Empreendorismo, Porto Alegre: Bokman, 2009.

BEUGELSDIJK, S.; CORNET, M., A far friend is worth more than a good neighbor: proximity and innovation in a small country. Journal of Management and Governance, V. 6, p. 169-188, 2002. 
CHAMINADE, C.; EDQUIST, C., Rationales for public policy intervention from a system of innovation approach: The case of VINNOVA. CIRCLE Electronic Working Papers, No. 2006/ 04, Lund University, 2006.

CLARYSSE, B.; WRIGHT, M.; MUSTAR, P., Behavioural additionality of R\&D subsidies: a learning perspective. Research Policy, V. 38, 1517-1533, 2009.

CORDER, Solange; SALLES FILHO, Sérgio. Aspectos conceituais do financiamento à Inovação. RBI - Revista Brasileira de Inovação, v. 5, n. 1, p. 33-76, 2009.

CORDER, Solange. A política de financiamento à inovação no Brasil. Revista Economia \& Tecnologia, v. 4, n. 3, 2012.

COSTA, Ana Czeresnia; SZAPIRO, Marina; CASSIOLATO José Eduardo. Análise da operação do instrumento de subvenção econômica à inovação no Brasil. Conferência Internacional LALICS - 2013, Rio de Janeiro, Brasil. Disponível em: http://www.redesist.ie.ufri.br/lalics/papers/88 Analise da operacao d.pd , acessado em 30 de março de 2014.

CRESWELL, John W. Projeto de pesquisa: Métodos qualitativo, quantitativo e misto. Tradução Luciana de Oliveira da Rocha. - 2.ed.- Porto Alegre: Artmed, 2007.

FELDMAN, M.P.; KELLEY, M.R. The ex ante assessment of knowledge spillovers: government R\&D policy, economic incentives and private firm behavior. Research Policy, V. 35, p. 1509-1521, 2006.

FINEP - Financiadora de Estudos e Projetos. Relatório de Avaliação do Programa de Subvenção 2010.2 Disponível em: $<$ http://download.finep.gov.br//programas/subvencao/subvencao_avaliacao1.pdf>, acessado em: 30 out. 2013.

FINEP - Financiadora de Estudos e Projetos. Relatório da Gestão do Finep 2003 2006 Disponível em: $<$ http://www.finep.gov.br/numeros finep/relatorio atividades/relatorio da gestao 20 03 a 2006.pdf $>$, acessado em: 30 out 2013.

FINEP - Financiadora de Estudos e Projetos. Manual de Programa de Subvenção Econômica à Inovação Nacional. Disponível em: http://download.finep.gov.br//manuais/manualSubvencao2010.pdf, acessado 18 março de 2014.

FONSECA, Renato. Inovação tecnológica e o papel do governo. Parcerias Estratégicas -Revista do Centro de Estudos Estratégicos do Ministério de Ciência e Tecnologia, Brasília, DF, n.13, p.69, dez. 2001.

FREEMAN, C.; SOETE, L. The economics of industrial innovation. Cambridge, Massachusetts: The MIT Press, 1997. 
IBGE. Pesquisa de Inovação Tecnológica 2008. Rio de Janeiro, 2010. Disponível em:

$<$ http://www.pintec.ibge.gov.br/downloads/PUBLICACAO/Publicacao\%20PINTEC\%2 02008.pdf>. Acessado em: 17 Nov. 2013.

IBGE. Pesquisa de Inovação 2011. Rio de Janeiro, 2013. Disponível em: http://www.pintec.ibge.gov.br/downloads/pintec2011\%20publicaca0\%20completa.pdf acessado em 18 março 2014.

OECD. Manual de Oslo: Proposta de Diretrizes para Coleta e Interpretação de Dados sobre Inovação Tecnológica. FINEP, 2004. Disponível em: www.finep.gov.br/imprensa/sala imprensa/manual de oslo.pdf. Acesso em: 30 Nov. 2013

PUFFAL, Daniel P.; PUFFAL, Clair W. Uma avaliação da cooperação no setor de componentes para calçados do Vale do Sinos. Gestão e Desenvolvimento. Volume 11, Num 1, p. 135 a 147, 2014.

RAPINI, Márcia Siqueira; DE OLIVEIRA, Vanessa Parreiras; SILVA NETO, Fábio Chaves do Couto e. A natureza do financiamento influencia na interação universidade-empresa no Brasil. Revista Brasileira de Inovação, v. 13, n. 1 jan/jun, p. $77-108,2013$.

ROMIJN, H.; ALBALADEJO, M., Determinants of innovation capability in small electronics and software firms in southeast England. Research Policy, V. 31, p. 1053-1067, 2002.

SALERNO, Mario Sérgio; KUBOTA, Luis Claudio. Estado e inovação. In: DE NEGRI, João Alberto; KUBOTA, Luis Claudio. (Org.) Políticas de incentivo à inovação tecnológica no Brasil. Brasília: IPEA, 2008.

SCHUMPETER, J. A. Teoria do desenvolvimento econômico: uma investigação sobre lucros, capital, crédito, juro e ciclo econômico. Tradução de Maria Sílvia Possas. São Paulo:

Nova Cultural, 1982.

SILVERMAN, David. Interpretação de dados qualitativos: métodos para análise de entrevistas, textos e interações.Tradução Magda Franca Lopes - 3ํㅡ. Ed. Porto Alegre: Bookman, 2009.

SOUITARIS, V., Technological trajectories as moderators of firm-level determinants of innovation. Research Policy, V. 31, p. 877-898, 2002.

TIDD, J; BESSANT, J.; PAVITT, K. Gestão da inovação. Tradução Elizamari Rodrigues

Becker et al. 3. ed. Porto Alegre: Bookman, 2008.

WALLSTEN, S.J., The effects of government-industry R\&D programs on private $R \& D$ : the case of the small business innovation research program. RAND Journal of Economics, V. 31, p. 82-100, 2000. 
Revista Tecnologia e Sociedade, Curitiba, v. 11, n. 21, jan./jun. 2015

ISSN (versão online): 1984-3526

ISSN (versão impressa): 1809-0044

YIN, R. K. Estudo de caso: planejamento e métodos. Trad.: Daniel Grassi. 3ª . Ed. Porto

Alegre, Bookman: 2005 